\title{
The SER Spread Under the ECB Quantitative Easing
}

\author{
Jakub Jakl
}

\begin{abstract}
:
This paper discusses the effects of the ECB's asset purchase programmes (APPs) on the SER spread, while the main focus is given to detail intraday analysis of implementation of the Public Sector Purchase Programme (PSPP). The SER spread is perceived as an important indicator of interbank trust in the Eurozone and its elevated level normally signals distortion and mistrust among commercial banks with a power to spill over into the whole financial sector. Recent development on interbank markets and especially within monetary policy in the Eurozone could have impaired the ability of the SER spread to act as a proxy for global systemic risk. The SER spread in this study was constructed and calculated using relevant European financial data and the consequent analysis was made on intraday and high-frequency (HF) 2015-2017 data. The ECB's APP, mainly PSPP, together with other instruments of monetary policy have impact on both legs of the SER spread and this paper tries to identify and quantify the degree of this effect by detailed HF market data analysis. HF intraday approach analysis is also being implemented in order to identify which leg of the SER spread was decisive in determining the SER spread change in the first three years of the PSPP implementation. Whether it was the "sovereign bond-based leg" directly affected by the ECB's PSPP purchases or the "interbank lending / STIR-based leg".
\end{abstract}

Key words: TED Spread; SER Spread; Quantitative Easing; ECB; PSPP.

JEL classification: E43; E52; E58; G21.

\section{Introduction}

Prior to the Credit crunch in 2007, not everyone knew what the TED spread is. The Treasury-Eurodollar spread (TED) was originally the spread between threemonth (3M) futures contracts on U.S. Treasuries and three-month (3M) Eurodollar, both quoted on the Chicago Mercantile Exchange (CME), till the 1987 stock market crash. Since then, CME dropped the futures on U.S. Treasury bills (T-bills) and the TED is calculated as a difference between the interest rate payed by the U.S. Government on 3M cash T-bill and 3M USD LIBOR rate, which

\footnotetext{
* Jakub Jakl: University of Economics, Prague, Faculty of Finance and Accounting, Department of Monetary Theory and Policy, W. Churchill Sq. 4, 13067 Prague 3, Czech Republic, <jakljakub@email.cz>.

The article is processed as an output of the research project Makrofinanční stabilita a finanční cyklus $v$ zemich s negativni čistou investični pozici registered under the registration number IGA F1/18/2017.
} 
represents the interbank lending market. TED is referred to as an indicator of the global systemic risk, e.g. in Bianchi, Drew and Wijeratne (2009), a measure of the liquidity freeze, as in Pringle and Carver (2009), or a credit risk indicator as it is referred to in Boudt, Paulus and Rosenthal (2013). In the wake of financial downturn events in 2007-2012, the TED spread became frequently mentioned and widely followed as a key indicator of market distress. In the Eurozone, the corresponding indicator is called the SER spread (Schatz-Euribor spread) and it is sometimes inaccurately referred to as the Eurozone TED spread. The SER spread is calculated as a difference between the interest rate payed by the German government on $3 \mathrm{M}$ cash T-bill (Bubill) and the $3 \mathrm{M}$ Euribor rate, which represents the interbank lending market. Since 2007, the factors that determine the SER spread have changed significantly and one of the main questions answered in this study is whether the SER spread still carries the same level of information about credit risk in the Eurozone economy.

The fact is that since 2007, almost everything connected with the TED / SER spreads changed heavily - monetary policy of the FED and the ECB changed from direct repo short-end yield curve rate-setting to unconventional Quantitative Easing (QE) and liquidity providing interbank money markets (both, collaterised and uncollaterised) undergone a long structure-changing process and the markets for sovereign bond obligations significantly changed as well. This study is focused on the Eurozone and it's SER spread since so far, there is literally non-existing research dedicated solely to the SER spread and impact of the ECB's monetary policy on this indicator.

Questions worthy to ask, that are answered in this study, are:

- Which leg of the SER spread prevailed in determination of the SER spread changes during implementation of the PSPP in 2015-2017 on intraday basis?

- How the scarcity of prime government bonds (German bonds) caused by the ECB's PSPP could have affected the market for collateral in the Eurozone and how was consequently affected the SER spread?

- What factors are the main factors in the SER spread determination in the current market and monetary-policy framework?

- How the hoarding of excess bank liquidity in the Eurozone, uncollaterised interbank market trends and shortage of prime sovereign bonds could have impacted the SER spread and is it causing the mitigation of the SER spread indicative abilities?

The rest of this paper has the following structure: the second section introduces the theoretical framework of the SER spreads and changes in the main factors that determined this indicator over the last decade (mainly monetary policy). The third section describes the data used further in this analysis and its limitations, followed by the fourth section with the methodology description and presentation of the 
results of the key high-frequency (HF) intraday analysis of futures markets for the German bonds and $3 \mathrm{M}$ Euribor. The fifth section contains the complementary descriptive analysis and the overall concluding discussion.

\section{The SER Spread Framework}

As mentioned above, the TED spread (the SER spread as an alternative for Europe) is commonly perceived as an indicator of distress in the banking sector. However, its nature as a spread means that there are two legs constituting this indicator and these legs can be either affected in the same way by some exogenous factor (e.g. monetary policy rates' change) or can be affected separately and with a different magnitude. To be a good indicator of the bank distress, it is necessary to capture deterioration of the interbank markets or distrust among commercial MFIs rather than other factors. There are many other factors and market forces that can suppress the indicative power of the SER spread. The same is mentioned e.g. in Goodfriend and McCallum (2007), where there are mentioned two categories of shocks - factors driven by shocks to the banking sector influencing the STIRbased $\operatorname{leg}^{1}$ and factors concerning collateral supply influencing the bond-based $\mathrm{leg}^{2}$. Relative changes in the price of collateral available to MFIs is one of the dominant factors that affect the SER spread nowadays, given the extensive APPs of the ECB and the consequent shrinkage of the available pool of prime sovereign bonds. Therefore, distinguishing between the collateral market shock and the banking shock driving factors provides a better interpretation of the TED or the SER spread as indicators of banking distress. There is possibly also a third group of factors that are inseparable from other factors and hard to study, namely manipulative actions connected to the London Interbank Offered Rate (LIBOR) and the consequent scandal.

In Figure 1 and Figure 2 below, there are depicted the TED and SER spreads during 2007-2013 and 2014-2018. Each figure represents a fairly different picture - the first one contains years of the Great Recession when both spreads, interlinked in today globalised world, reached their peaks during the elevated distress in the financial sector and the period of the European debt crisis peaking in 2011/2012. Part of this period between 2007-2009 could be characterised by the anchoring role of the sovereign bonds (bond-based leg) on the SER spread and rather changing conditions on the commercial banking side (the STIR-based leg). Different pattern is characteristic for the European debt crisis, with elevated yields of sovereign bonds in Europe, but this is another story and beyond the scope

\footnotetext{
${ }^{1}$ Short-term interest rates (STIR).

${ }^{2}$ In this paper, collateral purposes are mentioned and used in wider dimension - not only for repo purposes but also for interbank collateral purposes, legal reasons and other similar occasions when MFIs are motivated to hold and operate with high-liquid prime sovereign bonds.
} 
of this analysis. The second figure is much calmer in magnitudes of the TED and SER spreads and is characterised by the long-lasting period of stable monetary policy rates that were anchoring the STIR-based leg of the SER spread and rather disturbed on the side of bond-based leg - disturbed by the unconventional ECB's asset-purchasing monetary policy.

\section{Fig. 1 The TED and SER spreads in 2007-2013 [in bp]}

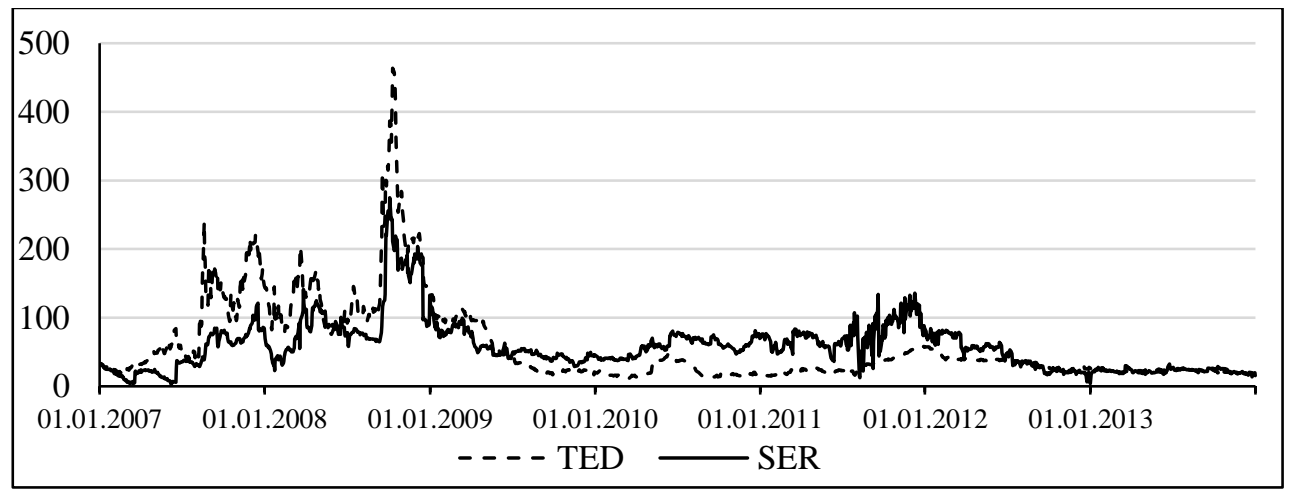

Source: FED, ECB, CME and Eurex Exchange; own calculations.

The path of the ECB's unconventional monetary policy began already in 2009 with the Covered Bond Purchase Programme (CBPP1) ${ }^{3}$ with the total value of EUR 60 billion, ending in 2010. In 2010, the Eurosystem started the Securities Markets Programme (SMP) ${ }^{4}$ with the total value of EUR 60 billion. The second Covered Bond Purchase Programme (CBPP2) followed soon after in 2011 and 2012 with the total value of EUR 16 billion of purchased bonds. In 2014, the Eurosystem's national central banks started the Asset Backed Securities Purchase Programme (ABSPP) and the third Covered Bonds Purchase Programme (CBPP3). In March 2015, the Public Sector Purchase Programme (PSPP), the largest asset purchase program aimed at sovereign bonds, was launched. And finally, in June 2016 has started so far the last APP program- the Corporate Sector Purchase Programme (CSPP) aimed at commercial non-financial bonds. The ECB's crucial programme for purposes of this analysis is the PSPP, which is by far the largest QE programme ever realised by the ECB, exceeding $80 \%$ of all the ECB's securities held for monetary policy purposes since early $2015 .{ }^{5}$ It was originally planned for 18 months but extended several times until the end of 2018. And most importantly, it was tailored and aimed at the secondary market sovereign eurodenominated bonds issued in the Eurozone. The ECB in its March 2015 Decision

\footnotetext{
${ }^{3}$ Aimed at the euro-denominated covered bonds issued in the euro area, same as two following waves of the CBPP.

${ }^{4}$ Aimed at the euro-area public and private debt securities markets.

${ }^{5}$ With total ECB holdings approximately around EUR 2,200 billion in December 2018.
} 
explicitly mentioned the PSPP as a measure taken in order to battle the downward drift in actual and expected euro area inflation and to give a push to the "lower than expected monetary stimulus from adopted monetary policy measures". In 2019, the ECB entered a new phase of asset purchases programmes, when only reinvestments are realized, while net purchases have ended. ${ }^{6}$

Unconventional policies of the ECB consisting of asset purchases, namely sovereign euro-denominated bonds under the PSPP, led to various effects and some of them may have been contradictory. The PSPP was officially designed to ease the financial and borrowing conditions of non-financial corporations and households in the Eurozone. While repeatedly ECB-emphasized role of the PSPP working mainly through portfolio balance channel leading from asset purchases to the final policy goal of price stability is explicitly mentioned, see e.g. Cœuré (2017), the potentially negative effects are presented with less enthusiasm. Altering of function of sovereign bonds as a collateral and high-liquid asset and demotivation of the Eurozone policymakers to implement fiscal austerity measures are two of them. Officially unspoken effect of the PSPP was in the first place lowering of the financing cost of federal governments in the Eurozone.

Positive results of the PSPP are uncovered e.g. in Paludkiewicz (2018) - he examines on granular data the Germany situation, when the PSPP-compressed bonds' yields led the Eurozone MFIs to rebalance their portfolios from securities bond holdings towards the credit portfolio, while the decrease in interest rates on the newly issued loans was lower than the decrease in the bond yields. His results indicate that banks increased their lending to non-financial firms and households in response to the lowering of bond yields and adequately decreased their bond holdings, especially those with highest drop in yields. This means that commercial banks were more willing to offer loans and yet the SER spread was widening through the bond-based leg. Since August 2012, there is also the phenomenon of growing excess liquidity of MFIs that come inevitably with the contemporary ECB monetary policy - liquidity providing programs (LTROs) together with asset purchases (for newly ECB-created interbank liquidity) and changes in the quality of the ECB collateral repo requirements contributed vastly to this current state. In this state of excess overall interbank liquidity, there is a general willingness to interbank lending but given the excess liquidity there is no need to borrow that much. This should in the contrary lower the SER spread through the STIR-based leg due to the lower pressure on the interbank market. Various empirical works

\footnotetext{
${ }^{6}$ On 13 December 2018, the Governing Council of the ECB decided to "... continue reinvesting, in full, the principal payments from maturing securities purchased under the APP for an extended period of time past the date when it starts raising the key ECB interest rates, and in any case for as long as necessary to maintain favourable liquidity conditions and an ample degree of monetary accommodation".
} 
examine the liquidity-driven rebalancing channel of MFIs, see e.g. Kandrac and Schlusche (2017) or Carpinelli and Crosignani (2017), and the yield-induced rebalancing channel; see e.g. Albertazzi et al. (2018) or Tischer (2018).

\section{Fig. 2 The TED and SER spreads in 2014-2018 [in bp]}

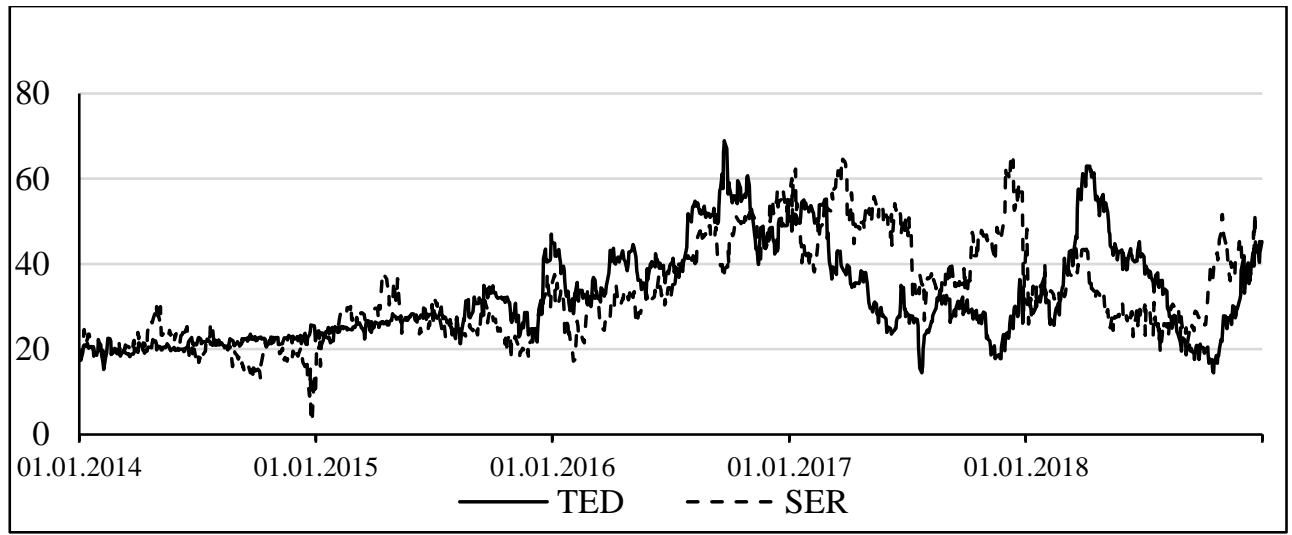

Source: FED, ECB, CME and Eurex Exchange; own calculations.

Under the PSPP, Deutsche Bundesbank (DB) (2018) purchased till the end of 2017 roughly around a quarter of the total outstanding volume of the German federal bonds (sometimes generally called Bunds), which induced major changes in the holders' structure. ${ }^{7}$ The holders' structure of German bonds is very broad because of its benchmark position among the European sovereign bonds and securities in general. The main Eurosystem counterparts were non-European foreign subjects followed by the euro area MFIs. The holders structure by residency from the pre- PSPP period in 2014 and 2017 changed significantly: non-euro area countries lowered their share from $59.8 \%$ to $44.6 \%$, German subjects tripled their holdings from $11.6 \%$ to $34.4 \%$, though that was entirely caused by the Deutsche Bundesbank's asset purchases (of which DB was 0\% to $23.5 \%$ ), other euro area countries lowered their holdings from $20.6 \%$ to $16.5 \%$ and other subjects with unclear residency accounted for $8 \%$ in 2014 and $4.5 \%$ at the end of $2017 .{ }^{8}$

An undesired side effect of the PSPP may have embodied an increased scarcity of the PSPP-targeted securities and consequently lower market liquidity with cash bonds caused by constriction of the sovereign bond markets - Eurosystem asset holdings were purchased to hold, not to trade. MFIs Bund bond holdings were crowded out by the DB purchases and the MFI's holdings changed from 5\% of the

\footnotetext{
${ }^{7}$ At the December 2017, the Bundesbank holdings accounted for $24 \%$ of total outstanding amount of German federal bonds ( $€ 263$ billion worth).

${ }^{8}$ Statistics provided by Deutsche Finanzagentur.
} 
total outstanding amount in 2014 to just $0,7 \%$, which is a significant decrease (86\% change). Other financial Eurozone investors also lowered their Bund holdings, though rather insignificantly - from $20.6 \%$ in 2014 to $20.1 \%$ in 2017. Important role of foreign country Bund holders as a counterpart of the ECB arise probably from the sales of China's public sector in this period when Chinese foreign exchange reserves shrank by USD 700 billion, as mentioned in Deutsche Bundesbank (2018). Estimated switch to free float of the tradable German bonds has shrunk to less than $40 \%$ of the total in December 2017. MFIs have, unlike other investors, access to the ECB deposit facility, which can be nowadays a cheaper and more convenient alternative to sovereign bonds, at least since the introduction of cash collateral option by the ECB in December 2016 (see ECB decision from 8 December 2016). While since March 2015 the ECB deposit facility rate (which is currently $-0.4 \%$ and negative since June 2014) exceeds the yield on $2 \mathrm{y}$ German federal bonds, it is at least from the yield-bearing perspective a better option than holding the short-end Bunds. This fact is probably the cause of the MFIs' Bund portfolio reduction; however regulatory requirements and the need to hold highly liquid assets for interbank collateral purposes and other reasons make the German bonds more than a simple investment with consequences to its price elasticity (respectively inelasticity). Regulatory environment with Basel III, the European Market Infrastructure Regulation (EMIR) and other regulations put on the Eurozone institutional investors could have induced a stronger and relatively price-inelastic demand for short-term and mid-term sovereign bonds, see the DB (2018). This effect is however opposed by the contradictory effect of excess liquidity of MFIs being held at its Eurosystem central bank. Striking difference between Eonia swap rate and yield on 2y German Schatz reaching over $60 \mathrm{bp}$ in early 2017 represents the so called "scarcity premium", which is referred to by the DB (2018) and can be used as a proxy to measure the relative scarcity of freely traded German securities.

As mentioned above, the ECB holdings were not designed to trade but rather to hold and to withdraw targeted assets from their markets - this could lead to the shrinkage of market liquidity (defined by the traded volume) as a side effect. Unlike the FED in its first wave of the QE that started in 2018, when asset purchases (mainly MBS) were designed to put frozen dysfunctional markets back into motion. Bund secondary market is mainly OTC and transactions outside the members of the Bund Issues Auction Group administrated by Deutsche Finanzagentur are publicly unknown. The given group however traded less than EUR 5,000 billion in 2017, while in 2005 it was EUR 7,000 billion, and the outstanding total volume increased circa one half during this period.

Janks and Mönch (2018) from the Deutsche Bundesbank contemplate over the European repo market, where the German sovereign bonds became scarce since 
2015 and with the concept of "specialness spread"9 analyse the distortion effect of the PSPP. German Bund is no longer being used as general collateral to the degree that it was used before the PSPP implementation. The repo market and reverse repo short-term purchases are mainly motivated by short position obligations, arbitrage transactions or liquidity provisions. They admit that "specialness is actually a phenomenon that should only occasionally arise for isolated securities" and that "specialness has been more the rule rather than the exception for German sovereign bonds in recent years." High unaccommodated demand for German bond was also associated with increased price volatility, while financial intermediaries tried to retain German sovereign bonds. Bunds are being considered safe and liquid, and financial intermediaries prefer not to repo them especially during the regulatory reporting dates as mentioned by the BIS (2013a) or (2013b).

Janks and Mönch (2018) also contemplate about the ECB securities lending facility, which was introduced in April 2015. Its purpose is to mitigate possible squeeze on bond markets where the PSPP-induced demand exceeds supply and the consequent price rise of the given bonds effectively withdraws them from daily use on the repo and collateral market due to their unavailability and high cost. ${ }^{10}$ The ECB has also adopted the cash collateral option in December 2016 for its repos (with a certain limitations) and tried to battle rising scarcity of the highly valuated sovereign bonds. The PSPP securities lending balances reached its highs in December 2017, when the average balance on loan was under EUR 70 billion. These actions, mainly introducing of cash collateral option, probably lead to the mitigation of the bond repo market pressures but the overall effect is disputable. Important fact to notice from Bindesil (2014) is that most bank assets are not refinanced through the central bank, in euro area it is just roughly around $2 \%$. MFIs also tend to use the least liquid eligible assets ${ }^{11}$ as collateral for the central bank and a sudden reduction in asset liquidity or tightening of the collateral framework can destabilize the short-term liabilities of commercial banks. While the ECB repo collateral requirements in the Eurozone were in recent years lowered in terms of the quality of collateral, available quantity of high liquid and safe sovereign bonds across the Eurozone was undoubtedly reduced and the overall resultant effect is therefore unclear.

\footnotetext{
${ }^{9}$ Which they defined as a difference between the ECB deposit facility rate and the specific collateral repo rate of a given bond.

10 The ECB made securities purchased under the PSPP and later under the CSPP available for lending in a decentralised manner by Eurosystem central banks since 2 April 2015.

${ }^{11}$ In the Eurozone, government bonds constituted in $2010 \mathrm{cca} 50 \%$ of eligible assets from the total assets and yet the usage ratio of government bonds was only around $6 \%$ in contrast to the ABS usage ratio of $38 \%$. See Bindesil (2014).
} 
Unconventional monetary policy of asset purchases implemented by the ECB could have impaired the ability of the SER spread to act as a proxy for global systemic risk. The SER spread is in model scenario mentioned as an indicator of elevated financial systemic risk, with an overall higher default risk of financial intermediaries; this, however, would not be true in the PSPP times when obviously widening of the SER spread was caused by the demand-driven price rise on the European sovereign bond markets. The following sections contain a description of the data and methodology, HF analysis of intraday SER-constituting data, complementary descriptive analysis and general concluding discussion.

\section{Data and Data Handling}

The upcoming Section 4 contains the essential part of this paper - high-frequency (HF) analysis of the SER spread based on detailed analysis of both the constituting legs (the bond-based and the STIR-based leg). Data for detailed analysis of the PSPP and OTC bond markets are virtually unavailable or available on insufficient frequency, therefore ultra HF futures data (exhaustive trade-by-trade from market data feed) were acquired from two exchanges. The Eurex Exchange (Deutsche Börse AG) is the source of data for the German bond futures and the London International Financial Futures and Options Exchange (LIFFE) is the source of data for Euribor ${ }^{12}$. Ultra HF data obtained from data sources were for convenience aggregated in 5second intervals, which is an optimal interval for analysing price changes on the given markets. ${ }^{13}$ For complementary analysis, where HF would not provide better insight, daily data were used, namely for correlation analysis between the German bonds with various maturity and the descriptive statistics. Sources for daily data are the same as for HF data extended for the Deutsche Finanzagentur, the ECB and Bloomberg.

Underlying Euribor data were also adjusted for flipper activity ${ }^{14}$, which would otherwise reduce data quality and usability. Underlying data were originally used for analysis of possible arbitrary trade opportunities caused by unsynchronised (time discrepancy) repricing of the underlying legs of the SER spread.

\footnotetext{
12 The reason why Euribor is used instead of Euro LIBOR interest rates, as it is usually used for computation of the TED spread (US LIBOR), is that LIBOR is constructed over few selected constituent MFIs and Euribor is constructed over much broader constituent base. Euribor is also used as a benchmark reference rate for financial contracts in the Eurozone.

${ }^{13}$ Given the fact that this paper does not aim to undergo the trade-by-trade analysis. This kind of analysis would be interesting if the ECB would ever published detailed information on its purchases (ISIN, day and hour of purchase, etc.); this is, however, unlikely going to happen.

${ }^{14}$ Illegal activity falling under market manipulations, when a subject alters the market conditions for a short period of time (usually by the size of a market order) by false signals and consequently carries out trades for its own benefit.
} 
As mentioned above, data for detailed analysis of the PSPP and OTC bond markets are virtually unavailable. This is the primary reason for adoption of the type of analysis presented in this paper rather than the more conventional, direct methods. Data regarding the QE of the Eurosystem, such as the PSPP, are confidential and only the aggregated and low frequency data are available. There is for instance no direct way how to find out when Deutsche Bundesbank (or other PSPP-authorised member banks of the Eurosystem) operated on bond markets. Interbank OTC money markets and OTC bond markets data are decentralised and very highly valuated and usually not provided (at least not on a sufficient frequency). Therefore, analysis undertaken in this section uses proxy data for their better availability and their HF character. Data to proxy the STIR-based leg come from the LIFFE ${ }^{15}$ Euribor futures contracts and data to proxy the bond-based leg come from the Eurex Exchange Schatz futures contract (FGBS). Euribor futures is cash settled future based on the European Money Markets Institute (EMMI) EURIBOR rate for three month deposits and the Eurex Exchange Schatz futures is futures whose underlying instrument is a short-term debt instrument issued by the Federal Republic of Germany. There are several strong reasons to believe that futures market data are convenient to act as a proxy: all OTC transactions are immediately reflected by the OTC market participants on futures markets for hedging or arbitrage purposes ${ }^{16}$, futures contracts are standardised in terms of maturity and futures are settled on the cheapest-to-deliver (CDT) basis and the bond futures market is widely perceived as the leading price formation element.

The original SER spread (as presented in the previous sections) is in this section replaced by its variation with a longer maturity, which was necessary in order to strip several Euribor expirations with different maturity to the corresponding Schatz futures (which has 1.75 to 2.25 years in the remaining term) ${ }^{17}$ Calculation of the SER spread in this section therefore incorporates the Germany cash bond (Schatz) hedged by strip or bundle of STIR futures (Euribor). In fact, it is a designed trade where quarterly cash flows of $3 \mathrm{M}$ STIR futures are hedged by cash flows of the given cash bond.

The sequence of mathematical determination of the SER spread is in general as follows:

- Construction of the implied coupon-paying generic bond from STIR futures (Euribor for the SER spread, or Eurodollar for the TED spread), which has the

\footnotetext{
${ }^{15}$ London International Financial Futures and Options Exchange (LIFFE).

${ }^{16}$ E.g. correlation coefficient value for Schatz futures and generic 3M Germany Bubill in 2014-2017 is 0.97 .

17 For the TED spread it would require the same procedure - strip Eurodollar expirations or Eurodollar bundle to the corresponding US Treasury cash bond.
} 
same characteristics as the corresponding cash bond. This implied generic bond is constructed using interest rates computed from the prices of STIR futures.

- Constructed implied generic bond then has the same credit rating as a strip from the given STIR futures.

- Difference of the interest rate of the constructed implied generic bond (its implied yield) and the interest rate of the actual cash bond (yield of the cheapest to deliver [CTD] cash bond $)^{18}$ is the SER spread.

The procedure described above requires in general terms many partial operations that make this procedure quite complex and its formal description would be too space-demanding, therefore only a brief text description follows in next paragraph. For all general financial mathematic procedures used in this paper, in this case with the focus on fixed income and STIR derivatives, see Choundhry (2003), Choundhry (2006), Aikin (2012) and Aikin (2006) or variety of other relevant financial mathematics publications on the given issue.

For convenience, the $\mathrm{CTD}^{19}$ cash bonds were chosen from the available set of cash bonds in this analysis for computation of implied prices and yields of STIR contracts. Cash flows of the CTD cash bond for each day were deployed on the corresponding cash flows of STIR contracts. Yield curve of spot interest rates was used to compute the interpolated interest rate valid for the STUB period, which is the period before the operationality of the first STIR contract of the used strip. Accrued interest was used to find the correct yield by deducting it from the so called dirty price bond. Conversion factor and gross basis were employed to transform the price of given bond futures to the price of a synthetic generic cash bond. Net basis based on the days to delivery, accrued to delivery and spot interest rates were then used to estimate the price of the cash bond more accurately.

\section{Intraday High-Frequency SER Spread Analysis}

Unlike the intraday analysis, high-frequency (HF) intraday analysis of the SER spread can reveal many things that would otherwise remain hidden. HF for instance shows the detailed traffic on individual markets for government bonds and the interbank market - volatility changes and peaks during the trading hours, intraday traded volumes and many other market characteristics that would not be uncovered using the daily aggregated data. Therefore, in this section the HF approach was adopted to uncover the possible causality among the two legs constituting the SER spread, which is crucial in order to identify the possible impact of the PSPP on the SER spread. Accompanying phenomenon indicating strong impact of the ECB's PSPP on the SER spread would be the dominance

\footnotetext{
${ }^{18}$ US $2 \mathrm{y}$ Bond for the TED spread and $2 \mathrm{y}$ Schatz for the SER spread

${ }^{19} \mathrm{CTD}=$ Current Bond Price - Settlement Price $*$ Conversion Factor
} 
of the bond leg on the SER spread changes during the PSPP implementation period. Causality would in this case simply go from the bond markets to the SER spread and consequently continue to STIR markets and this order of sequence would be observable on the HF data. Normally, each leg of the SER spread is accountable for a fair share of initiative role in the SER spread induced changes change in one leg (e.g. in the STIR leg) is being transferred to the other leg (e.g. the bond leg) and vice versa and there is no strong pattern or even prevalence of what comes first and what follows, respectively, which leg is the initiator, and which is the follower. There is also a reason to believe that during the PSPP implementation and presence of the ECB on the bond markets, the SER spread changes induced by the bond-base leg would not be fully accommodated by the STIR-based leg. Market participants would simply perceive changes on the bond markets to be long lasting and fundamentally grounded. ${ }^{20}$

The SER spread changes induced by the change on the bond leg were indeed not entirely accommodated by the change on the STIR-based leg, which is also observable on the data with lower frequency (daily, weekly, etc.). Changes on the STIR-based leg (Euribor-based) did not offset the changes on the bond-based leg which naturally led to an increase in the SER spread, this time with no real connection to elevation in the global systemic risk, interbank liquidity contractions or MFI credit default risk increase, as it was the case during the Great Recession.

The SER spread indicative power could have been therefore suppressed by its otherwise more stable constituent, bond-based leg. The real impact of the PSPP on the SER spread, however, could not be identified simply by looking at the Euribor rate and the yield of German Schatz since 2015, as captured in Figure 3. It gives us only the information about steadiness of Euribor and fluctuation of the Schatz yield especially in 2016 and 2017, while the real cause of this fluctuation remains unidentified. One way how to uncover the possible role of the PSPP without exhaustively identifying all other factors forcing the German yields lower is to focus solely on identification of the presence of the leading initiative role of the bond leg, which must have been caused by strongly elevated demand for the given bonds on related markets. Other factors that would be able to shake the SER spread through the bond-based leg, e.g. change of the sovereign rating

\footnotetext{
20 This could be theoretically caused by several reasons different for each leg. For the bond-based leg movement not to be accommodated by the STIR-based leg it can for instance cause fundamental change in the demand or supply side at sovereign debt markets. When e.g. the federal budget of some country exerts a surplus and the total outstanding amount of its debt is being reduced. On the STIRbased leg it could be caused by a change in the regulatory framework, collateral framework or newly established ECB liquidity facilities. The ECB is currently considering tiered deposit rate, meaning that some banks would be exempted from paying the ECB 0.40 percent annual charge on their excess reserves, see e.g. Koranyi, Siebelt and Canepa (2019).
} 
of Germany, would not have exerted this pattern of repricing on the bond markets through a series of many repricing episodes.

\section{Fig. 3 Euribor 3M rate and German generic 3m yield [in \%]}

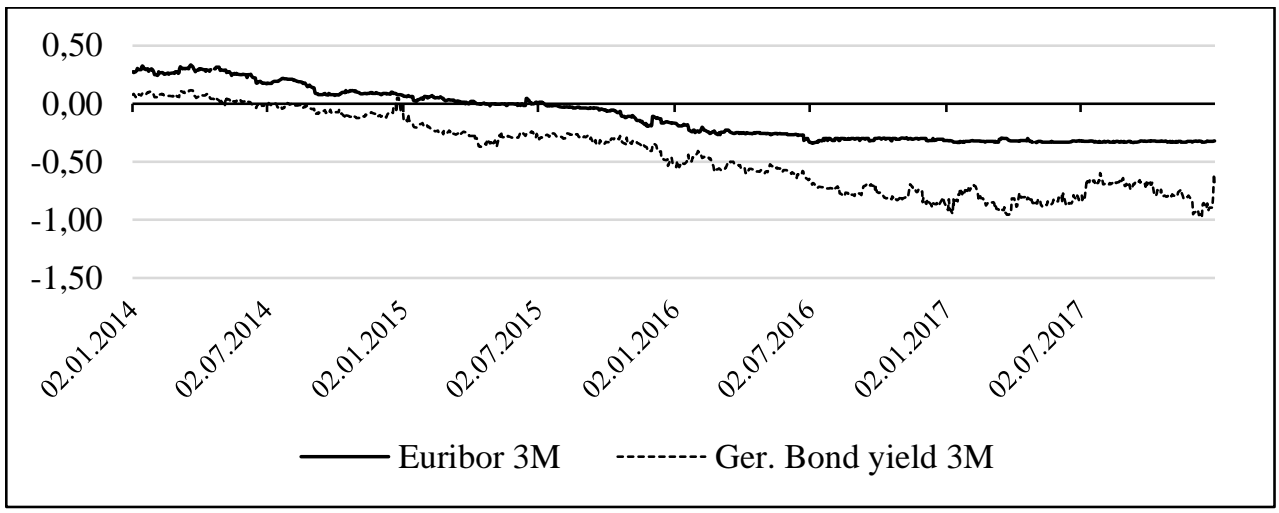

Source: LIFFE, Deutsche Finanzagentur.

Speaking of the German government bonds, they were not subject to sovereign rating (or rating outlook) changes for a long time - the last time when major rating agencies published Germany rating outlook changes was for Moody's Aaa stable (in February 28th, 2014), for S\&P AAA stable (in January 13th, 2012) and for Fitch AAA stable (in November 21st, 2011). During the European debt crisis (peaking in 2011-2012), the German bonds were the main relatively safe target of investors during the risk-off sale of less-sound sovereign bonds. Germany as a country also benefits from positive fiscal development and constantly reduces its debt-to-GDP ratio since $2012 .{ }^{21}$ This relative lower availability of the German sovereign bond has undoubtedly impacted the SER spread, but this is rather indirect through lower issuance of new bonds rather than buybacks of the existing debt; the secondary market is therefore influenced only indirectly through slow changes in the relative size of available bond pool. This gap between the supply and demand on the German bond market is however quickly widening due to the fact that nominal incomes and interest rates are rising in general and the sovereign bond issuance is being reduced.

\subsection{Clusterisation}

Gaussian Finite Mixture Modelling (GFMM) approach was used for clusterisation of three components of analysed data using $\mathrm{R}$ (programming language) package mclust, which is a package that allows modelling data as a Gaussian finite mixture with different covariance structures and different numbers of mixture components. Model-based clustering is in general described in more detail in Fraley and Raftery

${ }^{21}$ As reported by Bundesministerium der Finanzen. 
(2002) and in model-based cases using mclust package in Scrucca et al. (2016). Clusterisation undergone in this paper follows these mentioned sources and uses the modified version of VVV model described in Scrucca et al. (2016). In general term the GFMM can be described in following terms:

$x=\left\{x_{1}, x_{2}, \ldots, x_{n}\right\}$ is a sample of $\boldsymbol{n}$ independent identically distributed observations specified by a probability density function via FMM with $G$ components in the form of

$$
f\left(x_{i} ; \Psi\right)=\sum_{k=1}^{G} \pi_{k} f_{k}\left(x_{i} ; \theta_{k}\right),
$$

where $\Psi=\left\{\pi_{1}, \ldots, \pi_{G-1}, \theta_{1}, \ldots, \theta_{G}\right\}$ are the parameters of the mixture model, $f_{k}\left(x_{i} ; \theta_{k}\right)$ is the $k$ th component density for the observation $x_{i}$ with a vector of parameters $\theta_{k} .\left(\pi_{1}, \ldots, \pi_{G-1}\right)$ are the mixing probabilities (that sum up to 1 ) and $\mathrm{G}$ is the number of mixture components. $G$ is assumed to be fix, therefore the estimation of $\boldsymbol{\Psi}$ would be done by estimating the log-likelihood function $\ell\left(\boldsymbol{\Psi} ; x_{1}, \ldots, x_{n}\right)=\sum_{i=1}^{n} \log \left(f\left(x_{1} ; \boldsymbol{\Psi}\right)\right)$ respectively the MLE by expectationmaximization (EM) algorithm.

Gaussian mixture model (GMM), which assumes a multivariate Gaussian distribution for each component $f_{k}\left(x_{i} ; \theta_{k}\right) \sim \boldsymbol{N}\left(\boldsymbol{\mu}_{\boldsymbol{k}}, \boldsymbol{\Sigma}_{\boldsymbol{k}}\right)$, was employed in this study in a way that identified clusters are ellipsoidal, centred at the mean vector $\boldsymbol{\mu}_{\boldsymbol{k}}$ and with different geometric features (volume, shape, orientation) determined by the different covariance matrix $\boldsymbol{\Sigma}_{\boldsymbol{k}} . \boldsymbol{\Sigma}_{\boldsymbol{k}}=\boldsymbol{\lambda}_{\boldsymbol{k}} \boldsymbol{D}_{\boldsymbol{k}} \boldsymbol{A}_{\boldsymbol{k}} \boldsymbol{D}_{\boldsymbol{k}}$, where the scalar $\boldsymbol{\lambda}_{\boldsymbol{k}}$ controls the volume, $\boldsymbol{A}_{\boldsymbol{k}}$ is a diagonal matrix specifying the shape of the ellipsoid and $\boldsymbol{D}_{\boldsymbol{k}}$ is an orthogonal matrix which determines the orientation of the ellipsoid. Therefore volume, shape and orientation of the covariances are possible to constrain to be the same or to deviate between groups of clusters. Model VVV with different geometric characteristics was chosen for its best fit in our case, where $\boldsymbol{\Sigma}_{\boldsymbol{k}}=\boldsymbol{\lambda}_{\boldsymbol{k}} \boldsymbol{D}_{\boldsymbol{k}} \boldsymbol{A}_{\boldsymbol{k}} \boldsymbol{D}_{\boldsymbol{k}}$, distribution is ellipsoidal, and volumes / shapes / orientation are variable across clusters.

Generally, the number of mixing components and the covariance parameterisation are being selected using the Bayesian Information Criterion (BIC), which is not necessary in this analysis given the nature of data, where it is possible to easily identify three clusters per se. Optional arguments of $\mathrm{R}$ mclust package allow exact specifications for $\mathrm{G}$ - the number of components and the model covariances parameterisation. In this analysis, the EM algorithm for maximum likelihood estimation of multivariate mixture models was used to identify three clusters, whose characteristics were a priori specified. The identified component cluster [1] represents linear dependency between the constituting leg and the SER spread and it was a priori defined as a component with the highest variance (Gaussian cluster 
with covariance matrix corresponding to a long, thin diagonal ellipsoid) ${ }^{22}$, the second identified component cluster [2] was a priori defined as a component around y-axes (Gaussian cluster with covariance matrix corresponding to a long, thin, vertical ellipsoid around $y$-axes) and the third component cluster [3] capturing the rest of the observations that are rather randomly distributed.

Limitations of the model data are arising from the fact that all three clusters overlap around x-axes-y-axes intercept and it is not possible to separate them with high accuracy between clusters. ${ }^{23}$ Though it represents only a minor problem while it does not alter estimated slope of the fitted line in cluster [1] and gives us no strong information while this area around the coordinates $[0,0]$ contains only observations capturing very small movements of the leg against the SER spread itself. It can however alter the distribution among the clusters listed in Table 1, while this area often (in some days) contains majority of observations.

\subsection{Analysis results}

The following scatter plots of model outputs (plots made from intraday movements) in Figure 4 and Figure 5 are graphic representations of 5 second shots of the selected representative days:

The first scatter plot on the left in Figure 4 depicts relationship between cash bond price change in \% of par value (x-axis) and change of the SER spread in basis points (y-axis). The second scatter plot on the right in Figure 4 depicts the same relationship between the yield of constructed synthetic implied bond in basis points (x-axis) and the change of the SER spread in basis points (y-axis). Each presented scatter plot contains approximately ten thousand observations/points, both scatter plots are HF intraday from 22 January 2015, where the PSPP was introduced (planned to start in March 2015) by the ECB and monetary policy rates were unchanged. This decision was widely anticipated. This particular day was chosen for its representative look that is characteristic for the anticipation-period before implementation of the PSPP (end of 2014 and beginning of 2015) ending on this very day and for its unbiasedness that could be otherwise caused by the lack of liquidity or presence of major geopolitical events.

\footnotetext{
${ }^{22}$ With a negative slope for the bond-based leg yield change and with a positive slope for the STIRbased leg yield change.

${ }^{23}$ Derived density distribution was used to determine observations home clusters in the intercept.
} 


\section{Fig. 4 Cash bond price and implied yield relation to the SER before the PSPP [changes]}

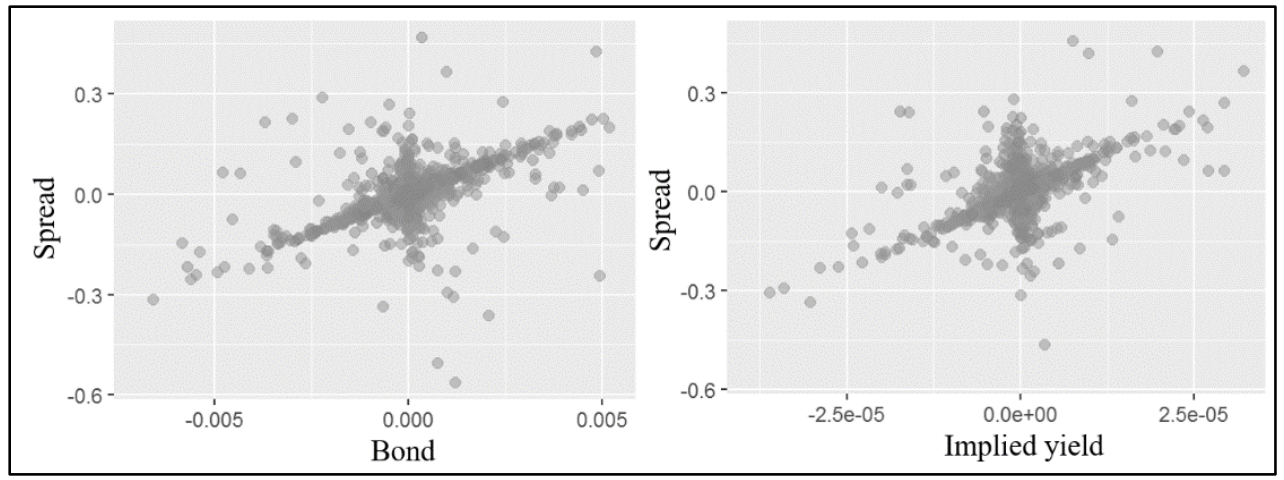

Source: own model calculations; Date: 22. 1. 2015; Units: basis points for SER, \% of par value for bond price, basis points* $10^{-4}$ for implied STIR yield.

From the plots it is clear that no leg of the SER spread is yet dominant in its impact on the SER spread change and though there is traceable linear dependence cluster on both plots, there are still majority of points suggesting a random quantity with two-dimensional normal distribution with $\rho=0$. These scatter plots still have a strong component that could be identified as statistically independent and was present significantly till the PSPP introduction. Statistical independency of both variables is especially characteristic for "normal" times before the period when asset purchases started to be anticipated (for 2013 and part of 2014), where there was no major leading force in the bond or STIR markets that would cause in the long run (days / weeks / months) some easily measurable change of the SER spread.

The situation is fairly different for the times during the PSPP implementation as it is visible on the scatter plots in Figure 5, which represents the common nonexceptional day from analysed period 03/2015-05/2017 of the PSPP under way. These are the same types of plots made from intraday movements at 15 December 2015. Both plots are now quite different from each other and it is clearer that movement in the cash bond price is accompanied by a linear change in the SER spread. Same cannot be doubtlessly said about the movement on the STIR-based leg (yield of the constructed synthetic implied bond). There are still some contours of a weak linear dependency - some changes of the SER spread were still induced by the change on the STIR-based leg. Nevertheless, majority of observations are either random (statistically independent) or with a strange relationship, when the change of the SER spread was not accompanied by the change in the yield of the constructed synthetic implied bond at all. These situations are probably caused by either lock in of very stable packs / bundles of the underlying STIR (Euribor in this case) or more frequently and importantly when the SER spread 
change is induced solely by the bond-based leg movement that is unaccommodated by the STIR-based leg movement.

For both cases, as for other days in the analysed time period, the direct relationship between both legs within the adopted time interval of 5 seconds exhibit crossshaped relationship - yield change on the bond-based leg caused no change on the STIR-based leg and vice versa. It either means that 5 seconds interval is too short to reprice change on the first leg to the second one or more probably that the relationship between both legs was somehow compromised during the given time period and that the market participants were reluctant to mirror changes from the first leg to the second one. Normally, it would be a tempting arbitrage opportunity.

\section{Fig. 5 Cash bond price and implied yield relation to the SER during the PSPP [changes]}

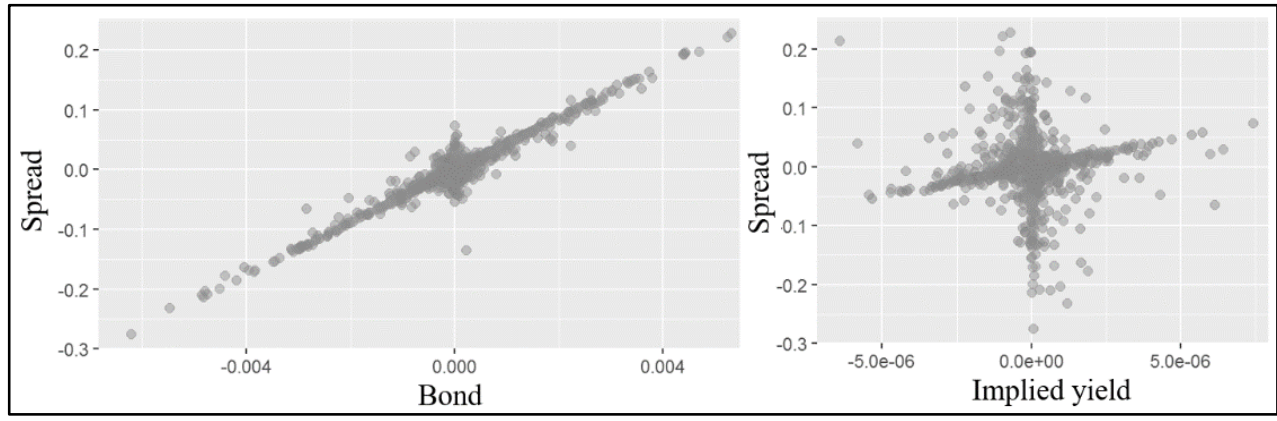

Source: own model calculations; Date: 15. 12. 2016; Units: basis points for SER, \% of par value for bond price.

The following Figures 6 and 7 represent exemplary model day that is more or less characteristic for the analysed time period, Figure 6 depicts a clustered relation between the bond-based leg yield change and the SER spread change and Figure 7 depicts a clustered relation between the STIR-based leg yield change and the SER spread change. On the HF data for 15 December $2016^{24}$ the scatter plots on Figures 6 and 7 were constructed by clustering methods (described in Section 4.1) and all observations were categorised as one of the three identified components [1] component that represents a linear dependency of the yield change of the given the SER spread leg, [2] component that contains all observations that are on the vertical line around y-axes and [3] independent component that represents other observations with no apparent dependency between the SER spread leg yield

\footnotetext{
${ }^{24}$ Regular day with no major macroeconomic event release, monetary policy decision, geopolitical factor or market liquidity irregularities in the Eurozone.
} 
change and the SER spread change. ${ }^{25}$ Especially important is the component [1] and the component [2]. Component [1] is strong for the bond-based leg and weak for the STIR-based leg, which is possible to interpret that the SER spread changes and the bond-based leg yield change is highly correlated and that the bond-based leg has very strong dominance in the given period in determining the SER spread unlike the STIR-based leg. Since we are speaking about a "spread", it is possible to directly speak about causality between the bond-based leg and the SER spread. Component [2] is on the contrary strong in the STIR-based leg and as mentioned before, it was probably caused by either lock in of the underlying STIR or situations when the SER spread changes were induced solely by the bond-based leg and were unaccommodated by the STIR-based leg. This would suggest that the market participants perceived a change in the SER spread backed up fundamentally and did not mirrored it to the Euribor.

\section{Fig. 6 Clustering of the cash bond yield relation to the SER spread [changes]}

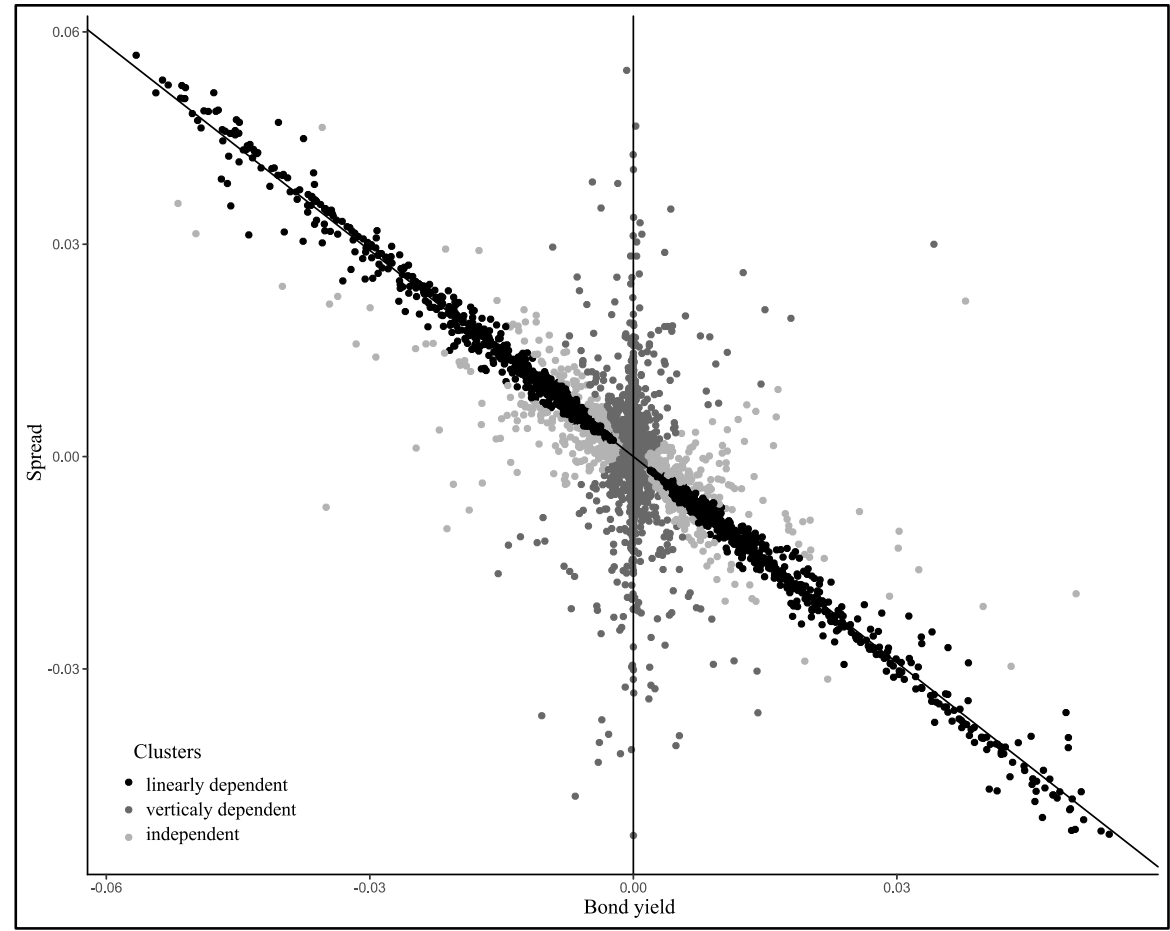

Source: own model calculations; Date: 15. 12. 2016; Units: basis points.

\footnotetext{
${ }^{25}$ Used method is only approximate and used in order to include in the components [1] and [2] only observations that clearly belong to that given category. The division of observations close to the center of the intercept of all components can be therefore slightly biased; however, reasonable assumption is that biasedness is rather small and not result-changing.
} 
Fig. 7 Clustering of the implied yield (STIR) relation to the SER spread [changes]

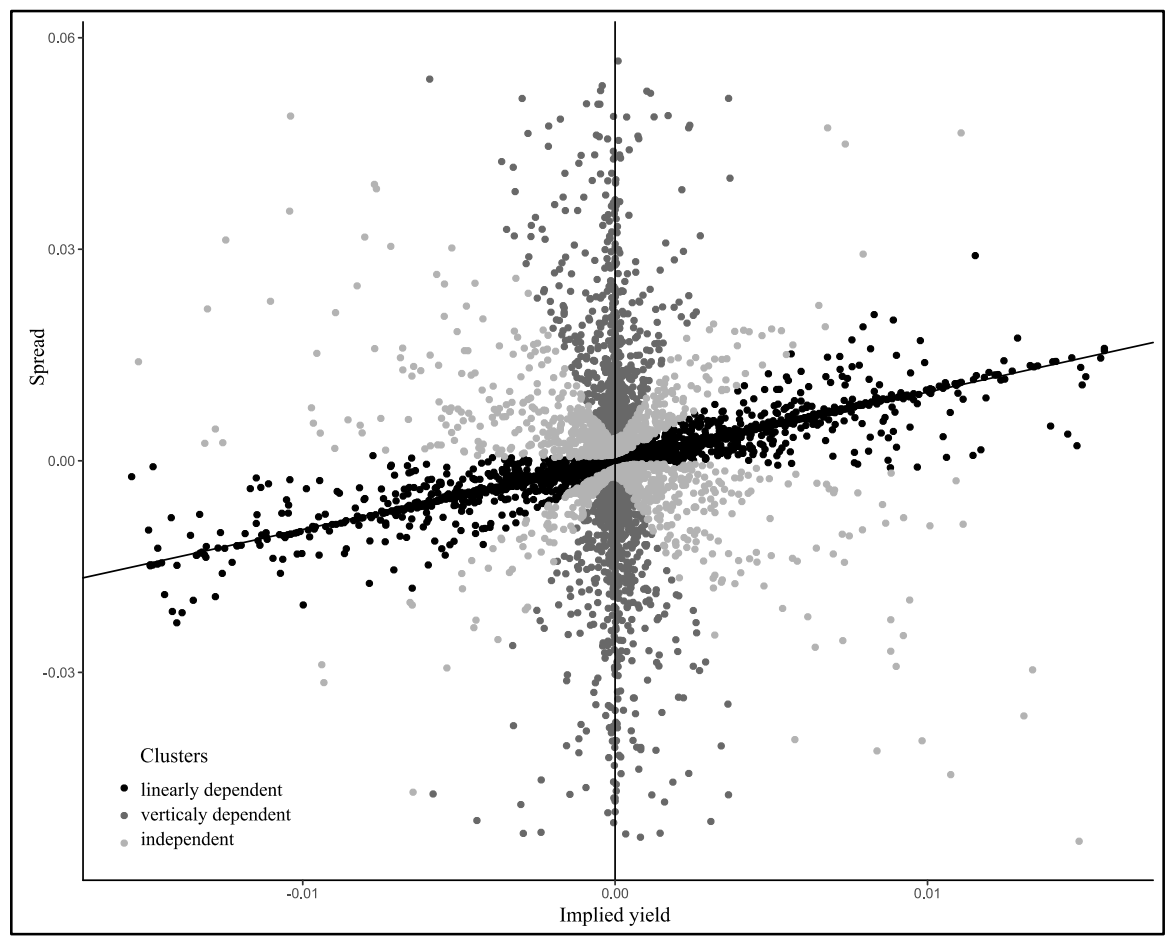

Source: own model calculations; Date: 15. 12. 2016; Units: basis points

The same clustering approach was applied on several other dates with approximately quarter year between them to capture the process dynamics and its output statistics are in Table 1. It is apparent that the slope of the line fitted through the component [1], representing the bond yield change to the SER spread change, is fairly stable through time and that this component includes the majority of observations as for the bond-based leg in 2017. This would suggest dominance of the bond-based leg over the STIR-based leg in determining the SER spread in 2017 (the SER change was induced only by the bond-based leg, not by both legs together by movement in the same direction), while for the STIR-based leg it is characteristic in 2017 that the component [2] includes majority of observations, which probably means that the STIR-based leg had very little influence on determining the SER spread. The slope of the fitted line through the component [1] of the bond-based leg is also very close to -1 which could be interpreted that these observations were not accompanied by an opposite direction movement of the STIR-based leg. 
Tab. 1 Descriptive statistics of selected days from 2016-2017

\begin{tabular}{|c|c|c|c|c|c|c|c|c|}
\hline Date & Leg & Component & $\begin{array}{l}\text { Obs. / tot. } \\
\text { obs. }\end{array}$ & $\begin{array}{l}\uparrow \text { Yield: } \\
\text { SER bp } \\
\text { change }\end{array}$ & $\begin{array}{l}\downarrow \text { Yield: } \\
\text { SER bp } \\
\text { change }\end{array}$ & SD leg & $\begin{array}{c}\text { SD } \\
\text { SER }\end{array}$ & Slope \\
\hline \multirow[t]{2}{*}{$6 / 14 / 2016$} & Bond & -1 & 1899 / 8626 & -15.59 & 18.17 & $3.4 \mathrm{E}-02$ & $3.4 \mathrm{E}-02$ & -0.986 \\
\hline & & -2 & $5936 / 8626$ & -0.35 & 0.61 & $1.3 \mathrm{E}-03$ & 4.6E-03 & $\infty$ \\
\hline \multirow[t]{2}{*}{$6 / 14 / 2016$} & STIR & -1 & $951 / 8626$ & 2.84 & -2.9 & $1.2 \mathrm{E}-02$ & $1.2 \mathrm{E}-02$ & 0.924 \\
\hline & & -2 & $532 / 8626$ & -2.18 & 2.62 & $9.6 \mathrm{E}-04$ & $6.0 \mathrm{E}-02$ & $\infty$ \\
\hline \multirow[t]{2}{*}{$9 / 29 / 2016$} & Bond & -1 & 2214 / 8626 & -8.45 & 9.21 & $2.0 \mathrm{E}-02$ & $2.0 \mathrm{E}-02$ & -0.983 \\
\hline & & -2 & 447 / 8626 & 0.74 & -0.34 & $1.1 \mathrm{E}-03$ & $1.9 \mathrm{E}-02$ & $\infty$ \\
\hline \multirow[t]{2}{*}{$9 / 29 / 2016$} & STIR & -1 & $373 / 8626$ & 2.2 & -1.6 & 2.2E-02 & $2.1 \mathrm{E}-02$ & 0.956 \\
\hline & & -2 & $617 / 8626$ & -2.17 & 3.17 & $8.2 \mathrm{E}-04$ & $3.7 \mathrm{E}-02$ & $\infty$ \\
\hline \multirow[t]{2}{*}{$12 / 15 / 2016$} & Bond & -1 & $2571 / 9345$ & -23.2 & 23.74 & $3.5 \mathrm{E}-02$ & $3.4 \mathrm{E}-02$ & -0.971 \\
\hline & & -2 & 5814 / 9345 & -0.54 & 0.54 & $1.2 \mathrm{E}-03$ & $5.3 \mathrm{E}-03$ & $\infty$ \\
\hline \multirow[t]{2}{*}{$12 / 15 / 2016$} & STIR & -1 & $5789 / 9345$ & 5.6 & -5.8 & $5.7 \mathrm{E}-03$ & $5.6 \mathrm{E}-03$ & 0.912 \\
\hline & & -2 & $1841 / 9345$ & -6.8 & 0.62 & $1.5 \mathrm{E}-03$ & $3.9 \mathrm{E}-02$ & $\infty$ \\
\hline \multirow[t]{2}{*}{ 03.01.2017 } & Bond & -1 & $7953 / 9345$ & -33.82 & 28.91 & $2.6 \mathrm{E}-02$ & $2.6 \mathrm{E}-02$ & -0.984 \\
\hline & & -2 & $1338 / 9345$ & -1.39 & 1.17 & $4.8 \mathrm{E}-03$ & $1.4 \mathrm{E}-02$ & $\infty$ \\
\hline \multirow[t]{2}{*}{ 03.01.2017 } & STIR & -1 & $1075 / 9345$ & 4.47 & -4.58 & $1.5 \mathrm{E}-02$ & $1.6 \mathrm{E}-02$ & 0.933 \\
\hline & & -2 & 8187 / 9345 & -9.76 & 4.64 & $1.4 \mathrm{E}-03$ & $2.6 \mathrm{E}-02$ & $\infty$ \\
\hline \multirow[t]{2}{*}{$5 / 18 / 2017$} & Bond & -1 & 7812 / 8626 & -37.4 & 36.93 & $2.4 \mathrm{E}-02$ & 2.2E-02 & -0.941 \\
\hline & & -2 & 714 / 8626 & -0.27 & 0.67 & $7.6 \mathrm{E}-03$ & 2.7E-02 & $\infty$ \\
\hline \multirow[t]{2}{*}{$5 / 18 / 2017$} & STIR & -1 & $758 / 8626$ & 6.57 & -6.17 & 2.7E-02 & $2.6 \mathrm{E}-02$ & 0.947 \\
\hline & & -2 & 7443 / 8626 & -9.56 & 8.79 & $1.9 \mathrm{E}-03$ & 2.2E-02 & $\infty$ \\
\hline
\end{tabular}

Source: own model calculations; Note: $\uparrow / \downarrow$ Yield: SER bp change is sum of all SER changes while leg yield went $\uparrow / \downarrow$.

In Figure 8 below, there is captured an interesting episode - time distribution of individual clusters through 12/08/2016, when the ECB released a decision regarding its monetary policy and held a press conference. MP rates were not changed, however the ECB in its decision prolonged APPs, introduced reinvestment framework for APPs, securities lending facility and allowed to use cash reserves as a repo collateral. From time distribution it is clear that before the decision the markets followed the pattern where bond (Bund) directly influenced the SER spread and this movement is not offset by Euribor (see component [1]). Around the decision and the press conference and for some time after that, the markets exerted a different pattern, rather uncertain, caused by unknown outcome of the ECB decision, when the components [2] and [3] gained some strength. 
However, at around $5 \mathrm{pm}$ the markets started to follow the same pattern as they followed the whole forenoon when it was clear that the ECB is going to hold the same direction of monetary policy and it is not willing to taper its asset purchases any time soon.

\section{Fig. 8 Time distribution of bond leg clusters (12/08/2016)}

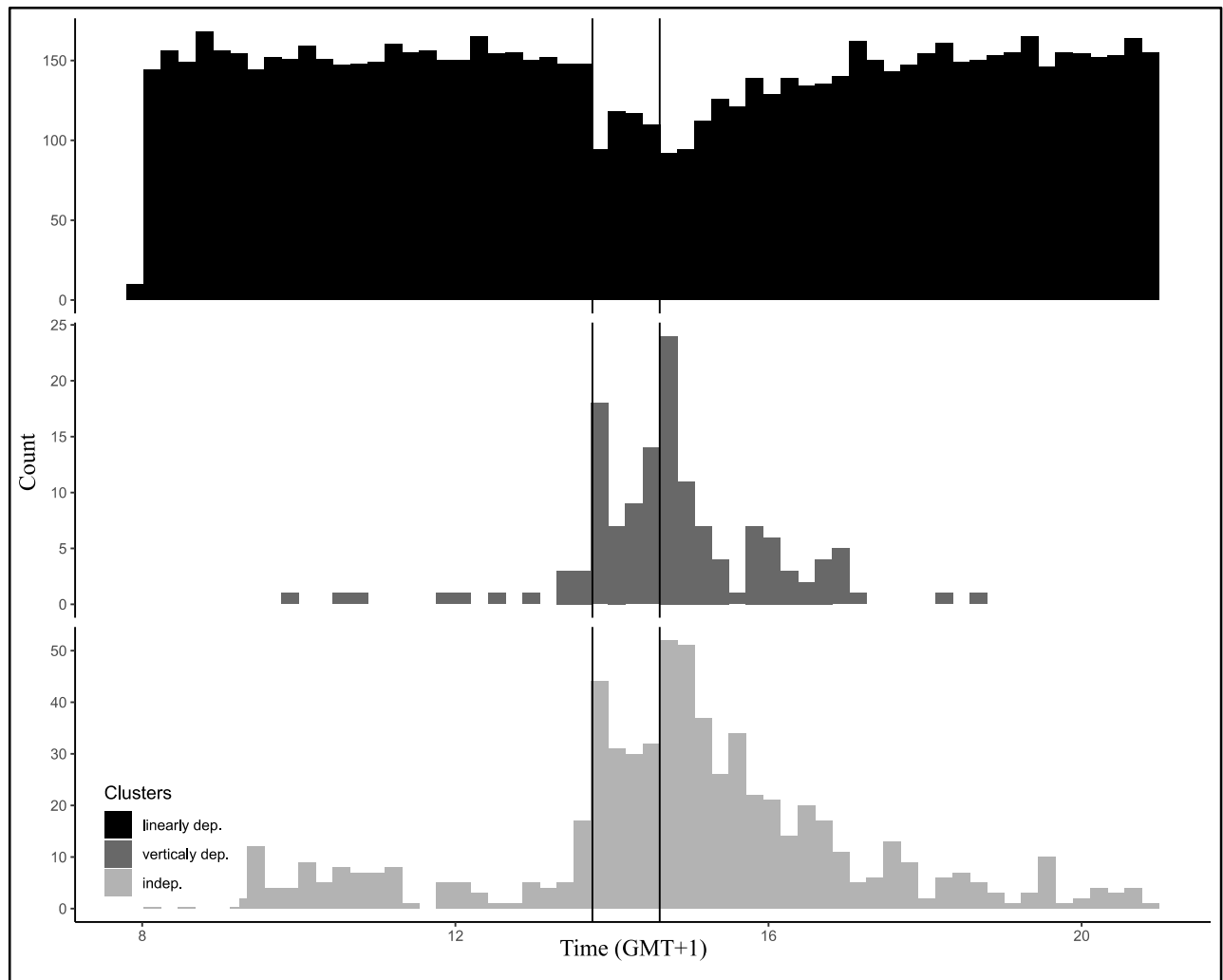

Source: own model calculations.

Altogether, this provides some indirect evidence about the real effect of the ECB's PSPP on the SER spread - at least it can be said that the strong or unaccommodated demand for the German bonds that caused prices to rise, and consequently stands behind the widening of the SER spread, was not caused by the forces that would affect both legs and it effectively eliminates many possible causes. For instance, the change in the ECB rate policy would affect both legs in the same direction and the SER spread would remain unchanged.

\subsection{Complementary descriptive analysis}

Some indicative power can also be attributed to simple descriptive statistic - 30day moving average of standard deviations (SD) of 3M Euribor and 3M German 
Bubill prices (see Figure 9) were elevated especially during the Great Recession years of 2008-2009 but were fairly comparable for both the underlying instruments. For the two following periods of the European debt crisis (20112012) and a calm period before the PSPP introduction, SDs are still very similar for the both underlying instruments. Same, however, cannot be said about the period of the PSPP implementation (2015-2017) displayed on the Figure 11, where SD of 3M German Bubill prices almost quadrupled SD of 3M Euribor. This period is with no doubt characteristic by higher German bond price volatility.

\section{Fig. $930 \mathrm{D}$ moving average standard deviation of 3M Euribor and 3M}

\section{German Bubill prices}

\begin{tabular}{l|cccc}
\hline & $\mathbf{2 0 0 8 - 2 0 0 9}$ & $\mathbf{2 0 1 1 - 2 0 1 2}$ & $\mathbf{2 0 1 3 - 2 0 1 4}$ & $\mathbf{2 0 1 5 - 2 0 1 7}$ \\
\hline 3M Euribor & 0.095402 & 0.054078 & 0.018862 & 0.008958 \\
3M GE Gov. Bond & 0.104255 & 0.069199 & 0.015057 & 0.033179 \\
\hline
\end{tabular}

Source: own calculations; Units: units of underlying contracts.

Intraday standard deviations of both legs and the SER spread on the time window of 3, 5 and 10 minutes intervals were constructed for all trading days in 01/201505/2017. Intraday SER spread SD carry no easily interpreted information but with respect to intraday SD of its legs it reveals the fact that increased SD on both legs at the same time does not necessarily increase SD of the SER spread; only unaccommodated movement of one leg would usually be transferred to increased SD of the spread between them.

\section{Fig. 10 30D moving average of SD of 3M Euribor and 3M German bond yield}

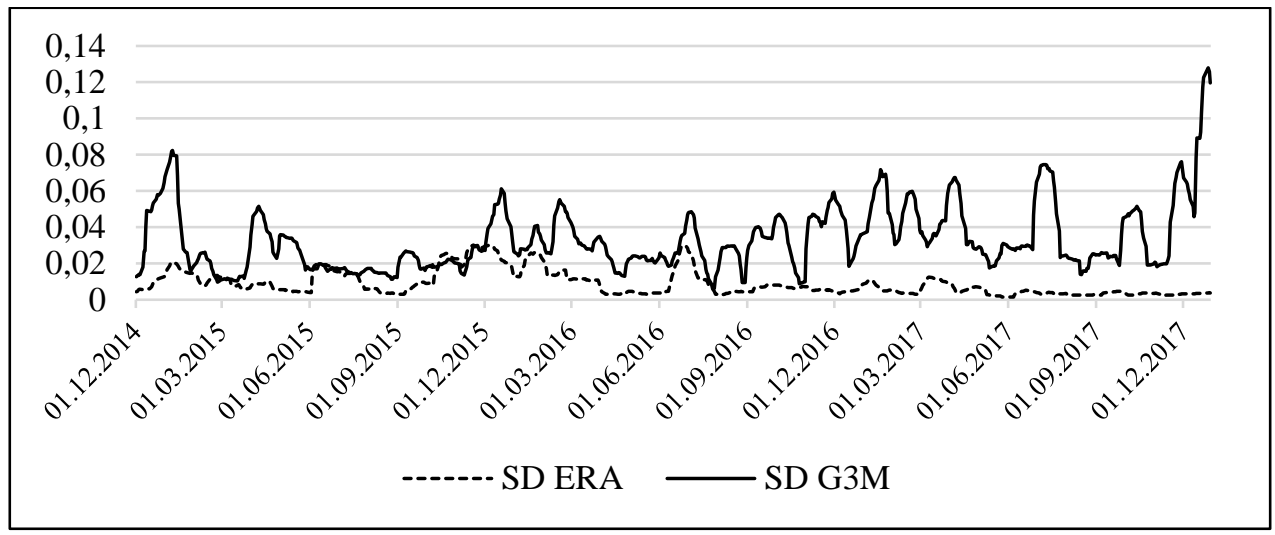

Source: Bloomberg / LIFFE, Deutsche Finanzagentur; Span: 12/2014-12/2017.

Another meaningful way is to look at the price correlation of different German cash bonds with various remaining maturity that gives us the information about the yield curve of the federal debt of Germany. Correlation naturally reacts swiftly and 
strongly to any change in market expectations regarding the ECB QE policy and its intentions to engage in asset purchasing. Price correlations of a spectrum of German sovereign bonds are depicted in Figure 12. Four main groups of bonds issued by the Federal Republic of Germany are represented by Schatz (remaining term 1.75 to 2.25 years), Bobl (remaining term 4.5 to 5.5 years), Bund (remaining term 8.5 to 10.5 years) and Buxl (remaining term 24 to 36 years) traded on Eurex Exchange in Germany. The ECB's PSPP weighted average remaining maturity of purchased German bonds was very close to 7 years for the period till December 2018. This part of the yield curve is represented by Bund and is by far the most traded contract among the German bonds. Figure 12 captures correlations between given bond maturities and was heavily affected by all important ECB decisions about its QE policy which is visible on several jumps around the decision dates. Base logic behind price correlation change is that when the ECB targeted certain yield curve part of sovereign bonds for asset purchases created significant pressure on its prices that was not fully transferred to other parts of the yield curve (longend). In 2016 and 2017 often mentioned tendency on the European fixed income markets was squeeze on the German bonds, when diminishing free float of tradable German bonds emerged, see e.g. Ashworth (2017) or Garzarelli and Cena (2015). Same logic stands behind the Operation twist announced by FED in 2011 causing the yield curve flattening by reinvestments of SOMA bond holdings to bonds with a longer maturity, see e.g. Swanson (2011).

\section{Fig. 11 Price correlations of the German bonds across maturity portfolio}

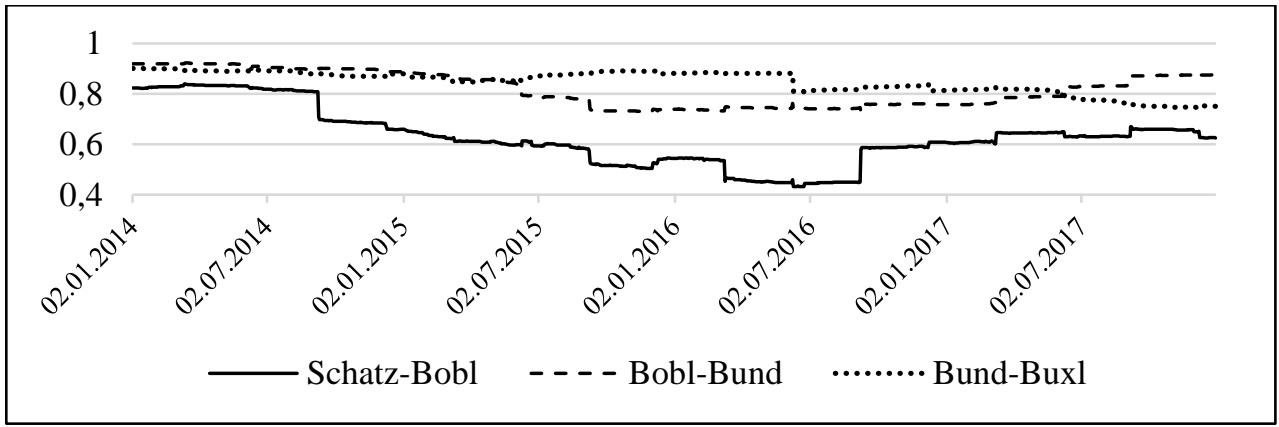

Source: Bloomberg / Eurex Exchange, Deutsche Finanzagentur; Span: 01/2014-12/2017.

There is a relatively calm period till the 09/2014 rate cut and introduction of the third Covered bond purchase programme $(\mathrm{CBPP} 3)^{26}$; an increase in the issue share limit for the purchased assets via the PSPP in September 201527; a rate cut, expansion of APPs and introduction of the Corporate Sector Purchase Programme (CSPP) and the second Targeted longer-term refinancing operations (TLTRO II)

\footnotetext{
${ }^{26}$ See monetary policy decisions of ECB from $4^{\text {th }}$ September 2014.

${ }^{27}$ See monetary policy decisions of ECB from $3^{\text {rd }}$ September 2015.
} 
in March 2016. ${ }^{28}$ Interesting is the sudden jump on the correlation of the short-end yield in September 2016, when no monetary policy change was implemented and which came later on in December, but the markets strongly expected a change in the asset purchase policy, see Murray, Powell and Sbaihi (2016). On the other hand, strongly anticipated major changes of monetary policy as the one announced in December 2016 was accompanied by only a minor price correlation change on Schatz-Bobl (increase) and Bund-Buxl (decrease) when the ECB announced another extension of APPs, lowered its eligibility criteria and introduced the cash collateral for PSPP securities lending facilities. ${ }^{29}$

Figure 13 below is a special non-standard tailored representation of the selected "special" days from within the analysed period 01/2015-05/2017 that were exceptional by some deviation from general characteristics: either by the cumulative change of the SER spread (MaxDiff) exceeding 1 basis point, the onetime change of the SER spread (MaxChange) exceeding 0.5 basis point, or the maximal intraday SD (MaxSD) of the SER spread exceeding 0.5 basis point. This graphic representation of the leg prevalence gives us a picture about gradual rise in importance of the bond-based leg over the STIR-based leg as the PSPP continued and the ECB accumulated holdings consisting from sovereign bonds. X-axis on Figure 13 is nonlinear in time because of the uneven time distribution of selected "special" days from dataset. Y-axis represents an average count of the daily occurrence of the biggest three SER spread changes induced either by the bond-based leg or the STIR-based leg. Separation of one group from other was undergone by Equation (2).

$$
\text { separation }=\left\{\frac{\left|i^{\text {impl }}\right|}{\left|i^{\text {impl }}\right|+\left|i^{\text {bond }}\right|} ; \frac{\left|i^{\text {bond }}\right|}{\left|i^{\text {impl }}\right|+\left|i^{\text {bond }}\right|}\right\}
$$

where $i$ stands for the change of the given leg specified in the upper index and lying within the interval $\langle 0,1\rangle$. Basically, only the SER spread changes where both legs moved in the same direction (one moved more than the other) or when one of the legs did not moved with the other are captured in the calculation. ${ }^{30}$ The SER spread changes which were characterised by the movement of both legs in the opposite direction were excluded for their ambiguousness. One important finding from the analysed period is causality direction - price changes on the STIR-based leg were usually followed by a price change on the bond-based leg and not the other way round. This is literally the technical reason why the SER

\footnotetext{
${ }^{28}$ See monetary policy decisions of ECB from $10^{\text {th }}$ March 2016.

29 See monetary policy decisions of ECB from $8^{\text {th }}$ December 2016 and press release where Eurosystem introduced cash collateral for PSPP securities lending facilities.

${ }^{30}$ Pair $\{0 ; 1\}$ or $\{1 ; 0\}$.
} 
spread widened, while prices of the German bonds rose, and this price movement was not mirrored on the STIR-based leg.

Fig. 12 The SER spreads selected days -3 top changes moving average leg dominance

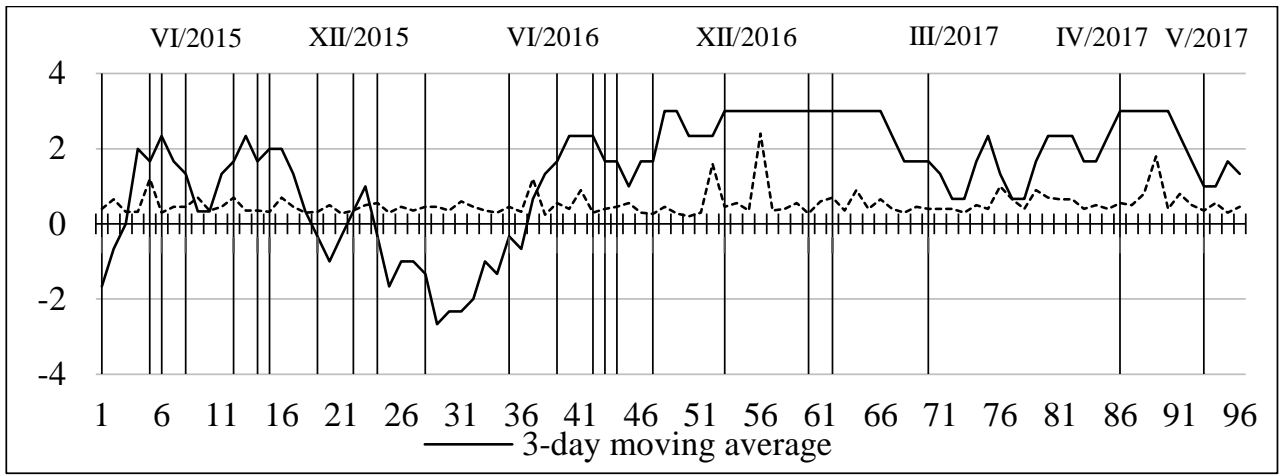

Source: own model calculations; Note: STIR leg (-) - Bond leg (+) sale, no occurrence of abnormal repricing of the SER spread in following months: 2015 (February, April, August), 2016 (April, May, August).

All the analyses presented above provide indirect evidence of strong market pressures that highly affected markets for the German government bonds and had undoubtedly a strong effect on the widening of the SER spread as well. Unavailability of relevant intraday data of the ECB purchases and the OTC nature of the cash bond markets unfortunately does not allow to carry out a more direct and straightforward kind of statistical analysis that would provide a direct evidence rather than an indirect one.

Overall, the analysis of HF data uncovered several interesting facts about the SER spread:

- In 2017, the SER spread reached its peak level not seen since the 2012 European debt crisis and its rising tendency is traceable since the end of 2014 and beginning of 2015. In that time, some kind of the ECB QE asses purchase program was highly anticipated.

- The bond-based leg constituting the SER spread (together with the STIR-based leg) is accountable for the majority of the SER changes, while it was not followed by the STIR-based leg. Especially the biggest repricing events / days in 2016 and 2017 were driven by this leg. This period corresponds with a squeeze on the prime euro-denominated sovereign bond market in the Eurozone, especially on the German bonds. 
- In 2015 and beginning of 2016, the STIR-based leg of the SER spread was still accountable for a non-negligible share of the SER change and this share gradually fell.

\section{Conclusions}

In this paper, the HF clustering analysis and complementary descriptive analysis uncovered the relation between the SER spread and its constituting legs, the first based on the short-term German government bond and the second based on the Euribor rate. Undertaken analyses are by their nature only indirect yet capable to uncover the connection of the ECB monetary policy, especially the PSPP, to the SER spread. Direct analysis of the PSPP purchases and their connection to the SER spread would require granular, ideally HF data, that are not provided by the Eurosystem. Weekly, monthly or ISIN-derived data capturing the Eurosystem asset purchases would not be sufficient to undertake a more direct analysis until the time of availability of exact data, when it will be possible to match purchases of the Eurosystem to the market trade-by-trade data.

HF analysis answered questions stated in the first section of this paper and uncovered several interesting facts about the SER spread and its constituting legs that would otherwise remain hidden. The central finding is that the bond-based leg was the SER spread determining leg since the beginning (or even since anchoring of the market anticipation) of the PSPP programme and this role even intensified later on in 2016/2017 when a squeeze on the prime bond markets hit hard its yields; unlike in the preceding times, when no leg had so overwhelmingly leading role in determining the SER spread. The role of the SER spread as an indicator of the financial market distress was seriously impaired and its recent elevations give us completely different information than it would be in case of the STIRbased leg dominance. The PSPP undoubtedly caused the shortage of prime sovereign bonds in the Eurozone and despite (because of that) the securities lending facility and the ECB collateral requirements changes it led MFIs and other institutional investors to significantly reduce their holdings of the German bonds. Among factors that impact the bond-based leg of the SER spread are not only the unconventional monetary policy of the ECB, there is also the shrinking federal debt of Germany caused by the budget surpluses in recent years, changing collateral framework and last but not least, slowly changing preferences of the domestic and foreign investors regarding the composition, riskiness and maturity of their investment portfolios. The STIR-based leg of the SER spread is currently very stable and the reality of abundant excess bank liquidity, effective functionality of the interbank money market, the ECB liquidity-providing programmes and the future prospect of still very dovish monetary policy contribute together to this current state. 


\section{References}

Albertazzi, U., Becker, B., Boucinha, M., 2018. Portfolio rebalancing and the transmission of large-scale asset programs: Evidence from the euro area. ECB Working Paper No. 2125, European Central Bank. Available from: <ecb.europa.eu/pub/pdf/scpwps/ecb.wp2125.en.pdf.> [22 July 2019].

Aikin, S., 2006. STIR Futures: Trading Euribor and Eurodollar futures. Harriman House LTD. ISBN: 978-0857192-19-6.

Aikin, S., 2012. Trading STIR Futures: An Introduction to Short-Term Interest Rate Futures. Harriman House LTD. ISBN 1-897597-81-9.

Ashworth, M., 2017. Germany's Worrying Squeeze: The worrying and systemic risks from a severe short bond shortage. 13 February 2017. Bloomberg Opinion. Available from: <bloomberg.com/opinion/articles/2017-02-13/germany-s-bondsqueeze-spells-the-end-of-draghi-s-rescue>. [22 July 2019].

Bank for International Settlements (BIS), 2013a. Asset encumbrance, financial reform and the demand for collateral assets. Committee on the Global Financial System - BIS, May 2013. ISBN 92-9197-935-X.

Bank for International Settlements (BIS), 2013b. Central bank collateral frameworks and practices. Markets Committee - BIS, March 2013. ISBN 929197-926-0.

Bianchi, R., Drew, M., Wijeratne, T., 2010. Systemic Risk, the TED Spread and Hedge Fund Returns. Discussion Paper No. 2010-04, Griffith Business School, Griffith University.

Bindseil, U., 2014. Monetary policy operations and the financial system. Oxford university press. ISBN 978-0-19-871690-7.

Boudt, K., Paulus, E., Rosenthal, D., 2013. Funding liquidity, market liquidity and TED spread: A two-regime model. National Bank of Belgium Working Paper No. 244. DOI: $10.2139 / \mathrm{ssrn} .2356236$.

Carpinelli, L., Crosignani, M., 2017. The Effect of Central Bank Liquidity Injections on Bank Credit Supply. Unpublished Working Paper.

Choundhry, M., 2003. The Bond \& Money Markets: Strategy, Trading, Analysis. Butterworth-Heinemann. ISBN: 978-0-7506-6078-5.

Choundhry, M., 2006. The Futures Bond Basis. Wiley. DOI: $10.1002 / 9781119208426$

Cœuré, B., 2017. The international dimension of the ECB's asset purchase programme. Foreign Exchange Contact Group meeting, 11 July, ECB, Frankfurt. Available from: <ecb.europa.eu/press/key/date/2017/html/ecb.sp170711.en.html/>. [22 July 2019]. 
Deutsche Bundesbank, 2018. Monthly Report Vol. 70, No. 7, July 2018, Deutsche Bundesbank. ISSN 1862-1325.

Fraley, C., Raftery, A., 2002. Model-based clustering, discriminant analysis and density estimation, Journal of the American Statistical Association, Vol. 97, No. 458, pp 611-631. DOI: 10.21236/ada459792.

Garzarelli, F., Cena, M., 2015. Where should German bunds trade? Goldman Sachs economic research. 5th March.

Goodfriend, M., McCallum, B., T., 2007. Banking and interest rates in monetary policy analysis: A quantitative exploration. Journal of Monetary Economics, 54(5), 1480-1507. DOI: 10.3386/w13207.

Jank, S., Mönch, E., 2018. The impact of Eurosystem bond purchases on the repo market. Deutsche Bundesbank. Research Brief No 21, September 2018.

Kandrac, J., Schlusche, B., 2017. Quantitative Easing and Bank Risk Taking: Evidence from Lending. Finance and Economics Discussion Series, 2017-125, Board of Governors of the Federal Reserve System. DOI: 10.17016/feds.2017.125. Koranyi, B., Siebelt, F., Canepa, F., 2019. ECB studying tiered deposit rate to alleviate banks' plight: sources. 27 March 2019. Thomson Reuters. Available from: <reut.rs/2V1IX1S/>. [22 July 2019].

Lewis, V., Roth, M., 2019. The financial market effects of the ECB's asset purchase programs. Deutsche Bundesbank. Discussion Paper No 23. DOI: 10.1016/j.jfs.2019.05.001.

Murray, J., Powell, D., Sbaihi, M., 2016. EURO-AREA PREVIEW: Draghi Looking Beyond March QE Horizon. 8 September 2016. Bloomberg.

Paludkiewicz, K., 2018. Unconventional monetary policy, bank lending, and security holdings: the yield-induced portfolio rebalancing channel. Discussion Paper No 22, Deutsche Bundesbank. DOI: 10.2139/ssrn.3214522.

Pringle, R., Carver, N., 2009. RBS reserve management trends 2009. Central Banking Publications, ISBN 1902182596.

Scrucca, L., Fop, M., Murphy, T., Raftery, A., 2016. mclust 5: clustering, classification and density estimation using Gaussian finite mixture models, The R Journal, Vol. 8 No. 1, 289-317. DOI: 10.32614/rj-2016-021.

Swanson, E., 2011. Let's Twist Again: A High-Frequency Event-Study Analysis of Operation Twist and Its Implications for QE2. Working Paper No. 08/2011, Federal Reserve Bank of San Francisco. DOI: 10.24148/wp2011-08.

Tischer, J., 2018. Quantitative Easing, Portfolio Rebalancing and Credit Growth: Micro Evidence from Germany. Discussion Paper No 20/2018, Deutsche Bundesbank. ISBN 978-3-95729-467-8. 